DOI: 10.12731/2070-7568-2019-2-22-34

УДК 338.22

\title{
ПРОГНОЗ ЭФФЕКТИВНОСТИ ПРОГРАММ ПО ИМПОРТОЗАМЕЩЕНИЮ (НА ПРИМЕРЕ СТАНКОСТРОИТЕЛЬНЫХ ПРОИЗВОДСТВ)
}

\author{
Бекмурзаев И.Д., Курбанов А.Х., Наружный В.Е.
}

Реализация программ импортозамещения в России требует отбора оптимального варианта их проведения. Для этого необходима оценка предполагаемой эффективности различных вариантов с точки зрения национальной экономики. Однако проведение такой оченки затруднительно из-за сложности доступа к необходимой информации.

Цель исследования: разработка и практическая проверка методики обоснования отбора оптимальной организационной структуры для развития импортозамещающих производств

Методология: анализ и синтез, экспертная оченка

Полученные результаты: на основе экспертных оченок показано, что оптимальным с точки зрения интегрального эффекта вариантов развития импортозамещуающих производств в станкостроении является формирование государственно-частного партнерства, ориентированного на выпуск станков.

Ключевые слова: импортозамещение; реиндустриализация; экспертная оценка; государственно-частное партнерство.

\section{FORECASTING THE EFFICIENCY OF PROGRAMS OF SUBSTITUTION OF IMPORT (MACHINE-BUILDING INDUSTRY)}

Bekmurzaev I.D., Kurbanov A.Kh., Naruzhny V.E.

Implementation of programs of substitution of import in Russia requires a selection of the optimal variant of their realization. This is why 
the efficiency of these variants should be evaluated from the point of view of national economy. But this evaluation is difficult due to the lack of necessary information.

Goal of the research: elaboration and practical testing of a method of substantiation of selection of an optimal organization structure for the development of facilities for substitution of import

Methodology: analysis and synthesis, expert evaluation

Results: the research demonstrates that the optimal variant of development of facilities for substitution of import in machine-building from the point of view of integral efficiency is the formation of public-private partnership, oriented towards production of machines.

Keywords: substitution of import; reindustrialization; expert evaluation; public-private partnership.

Станкостроение играет ключевую роль в инновационном развитии промышленности, поскольку оно, с одной стороны, создает спрос на передовые технологии в области мехатроники, программного обеспечения, материаловедения и т. д., а с другой стороны обеспечивает национальную экономику собственными высокотехнологичными производственными активами.

К сожалению, станкостроительная отрасль была в России практически утрачена после 1991 г. Это было связано как с отсталостью советского станкостроения, так и с развалом отечественной промышленности в целом, что устранило спрос на российские станки (а в ситуации, когда создавались новые производства, нуждавшиеся в станках, потребность в них закрывалась за счет иностранных поставок). Однако реализуемая в нашей стране программа реиндустриализации и импортозамещения [Вертакова, Плотников 2014] должна опираться на отечественное станкостроение, что создает стимулы к его развитию. Организация станкостроительных производств позволит выстроить современную высокотехнологичную промышленность, которая даст возможность не только обеспечить оборонно-промышленный комплекс (ОПК) необходимой производственной базой (не секрет, что импортозамещение реализуется во многом в интересах 
оборонной промышленности [Бочуров, Курбанов 2017], [Ерасова, Плотников 2017]), но и заложит основы для экономического роста нашей страны, устранения зависимости от поставок иностранных ресурсов и компетенций, увеличения доли добавленной стоимости, производимой в России, и эффективного участия российской экономики в мировом разделении труда. Именно эта задача - использование поддержки ОПК как инструмента развития национальной экономики в целом - является стратегической [Князьнеделин 2013], и поэтому в данной статье мы выдвинем наши рекомендации по обоснованию оптимального пути развития станкостроительных производств.

Как показывают отраслевые обзоры и исследования специалистов по экономике промышленности [Князьнеделин, Стариков 2015], [Стариков 2019], для выпуска современных высокоточных станков требуется организовать в России производство станин, систем числового программного управления (ЧПУ) нового поколения (позволяющих интегрировать оборудование в единый киберфизический комплекс), шпинделей и подшипников. Отметим, что системы ЧПУ включают в себя как материальный (компьютерное оборудование, датчики и т. д.) и нематериальный (программное обеспечение) компоненты. Это указывает на тесную связь между импортозамещением в ОПК и импортозамещением в станкостроении и открывает путь к применению результатов, полученных в ОПК, в интересах гражданской промышленности. Эта связь достигается благодаря организации в России производства собственной электронно-компонентной базы (ЭКБ), которая может быть использована как в изготовлении ВВТ, так и для выпуска станков. Таким образом, при выпуске ЭКБ в нашей стране необходимо ориентироваться в том числе и на нужды гражданской промышленности [Князьнеделин 2019]. Отметим, что спрос на ЭКБ будет расти благодаря происходящей четвертой технологической революции, что открывает возможности для организации в нашей стране не просто импортозамещающих производств ЭКБ, но созданию высокомаржинальной отрасли по выпуску ЭКБ, ориентированной на мировой рынок.

Состояние современной базы российской промышленности представлено в табл. 1. 
Таблица 1.

Современное состояние базы российской промышленности (составлено автором по материалам [Колерова 2019], [Ульянов 2018])

\begin{tabular}{|c|c|c|}
\hline $\begin{array}{c}\text { Элементы } \\
\text { производ- } \\
\text { ственной } \\
\text { базы }\end{array}$ & $\begin{array}{c}\text { Современное состояние } \\
\text { в России }\end{array}$ & $\begin{array}{l}\text { Препятствия } \\
\text { к развитию }\end{array}$ \\
\hline Станины & $\begin{array}{l}\text { Существует собственное про- } \\
\text { изводство, соответствующее } \\
\text { мировому уровню }\end{array}$ & $\begin{array}{l}\text { Экономические (высокая стои- } \\
\text { мость металла) }\end{array}$ \\
\hline $\begin{array}{l}\text { Системы } \\
\text { ЧПУ }\end{array}$ & $\begin{array}{l}\text { 1. Высокий уровень развития } \\
\text { производителей программного } \\
\text { обеспечения, способных само- } \\
\text { стоятельно обеспечить про- } \\
\text { мышленность программными } \\
\text { продуктами отечественной } \\
\text { разработки; } \\
\text { 2. Практически полное отсут- } \\
\text { ствие собственной ЭКБ }\end{array}$ & $\begin{array}{l}\text { Отсутствие собственных про- } \\
\text { изводств ЭКБ }\end{array}$ \\
\hline Шпиндели & $\begin{array}{l}\text { Устаревшие производства } \\
\text { (прецизионные шпиндели } \\
\text { завозятся из-за рубежа и охва- } \\
\text { чены санкционными ограни- } \\
\text { чениями) }\end{array}$ & $\begin{array}{l}\text { Отсутствие собственной кон- } \\
\text { структорской базы; } \\
\text { Нехватка государственной под- } \\
\text { держки разработки прецизион- } \\
\text { ных шпинделей; } \\
\text { Отсутствие собственного пре- } \\
\text { цизионного оборудования для } \\
\text { организации производства } \\
\text { собственных высокоточных } \\
\text { шпинделей } \\
\end{array}$ \\
\hline Подшипники & $\begin{array}{l}\text { Наличие собственных произ- } \\
\text { водств приемлемого уровня } \\
\text { качества, закрывающих почти } \\
\text { весь спектр потребностей } \\
\text { промышленности (за исключе- } \\
\text { нием отдельных видов высоко- } \\
\text { точных подшипников и специ- } \\
\text { альных подшипниковых узлов) }\end{array}$ & $\begin{array}{l}\text { Отсутствие собственного пре- } \\
\text { цизионного оборудования; } \\
\text { Недостаточное производство } \\
\text { специальных сталей; } \\
\text { Отсутствие государственной } \\
\text { поддержки; } \\
\text { Отсутствие опыта в проекти- } \\
\text { ровании и конструировании } \\
\text { специальных подшипниковых } \\
\text { узлов; } \\
\text { Отсутствие спроса со стороны } \\
\text { промышленности на высоко- } \\
\text { точные подшипники }\end{array}$ \\
\hline
\end{tabular}


Как показывает табл. 1, в России представлены практически все производства, необходимые для восстановления станкостроительной промышленности. Существуют и собственные станкостроительные производства. Однако зависимость от импортных поставок очень велика, причем даже в тех случаях, когда на рынке есть отечественные аналоги, потенциальные потребители (станкостроители и иные машиностроительные компании) отдают предпочтения продукции иностранного производства. Характерным примером может быть ситуация с Волжским подшипниковым заводом, один из цехов которого ориентирован на выпуск современных высокоточных подшипников для станкостроения. Этот цех в настоящее время простаивает, потому что станкостроители в России занимаются преимущественно сборкой станков из иностранных узлов и комплектующих, которые уже оснащены подшипниками.

К сожалению, значительная часть информация, необходимая для оценки целесообразности развития в нашей стране импортозамещающих станкостроительных производств, недоступна или засекречена, а для части информации невозможно получить точные оценки. Это же справедливо и для оценки уровня рисков для российской экономики, связанных с зависимостью от иностранных поставок промышленного оборудования. По этой причине мы не стали проводить точный расчет экономической и военной эффективности возможных вариантов организации станкостроения в России, а осуществили их экспертный анализ. В рамках такого анализа нами были опрошены 27 экспертов. По роду своей основной деятельности они специализируются либо в области научных исследований по военной экономике и/или экономике промышленности, либо в сфере руководства промышленными предприятиями.

В рамках опроса им было предложено оценить следующие перспективные варианты организации станкостроения в интересах ОПК Российской Федерации:

1. Учреждение государственной вертикально интегрированной компании, которая сосредоточит все ключевые этапы производства станков. Преимущество такого подхода заключается в возможности 
целевого государственного финансирования деятельности такой компании, постановки для нее четких задач, выполняемых в интересах государства, сохранения контроля над освоенным производством станков в руках государства;

2. Формирование государственно-частного партнерства (ГЧП), ориентированного на выпуск станков. В рамках такого партнерства будет отобрано уполномоченное частное предприятие, уже обладающее необходимыми компетенциями в сфере промышленного производства. Это предприятие будет привлекать (используя как инвестирование в другие компании, так и сетевое сотрудничество) формировать сетевую структуру, которая охватит весь цикл производства станков [Князьнеделин, Стариков 2015], [Стариков 2016], [Стариков 2017]. При этом все участники такой структуры будут находиться в Российской Федерации;

3. Создание ГЧП, которое сформирует сетевую структуру, ориентированную на выпуск станков. Отличием от предыдущей модели является то, что в России будет локализовано только производство станков и отдельных ключевых элементов, тогда как на более низких уровнях кооперации будут привлечены уже существующие поставщики из других стран (в первую очередь - из Китая).

Рекомендации по выбору оптимальной стратегии реализации проекта импортозамещения формируются по критерию максимального ожидаемого эффекта [Богатырева, Титов, Куприянова 2016].

Для каждого из этих вариантов участникам опроса было необходимо оценить значения прямого и косвенного экономического эффекта и военного эффекта (в дальнейшем, путем свертки, рассчитывался показатель интегрального эффекта). Оценка военного эффекта проводилась, так как проект развития импортозамещающих производств реализуется в интересах ОПК. Поскольку в абсолютном выражении определить эти величины невозможно из-за нехватки информации, участникам опроса было предложено оценить эти эффекты в относительном выражении. В качестве базового варианта был принят вариант один (для которого значения прямого и косвенного экономического эффекта и военного эффекта были приняты 
равными 1). Выбор этого варианта в качестве базового объясняется тем, что для институциональной среды России наиболее типичным способом реализации стратегических проектов является создание уполномоченной государственной компании.

Итоговые значения для каждого варианта (полученные путем усреднения ответов экспертов) представлены в табл. 2.

Таблица 2.

Результаты расчетов прямого и косвенного экономического эффекта и военного эффекта от различных вариантов импортозамещения в станкостроении (составлено Наружным В.Е. на основе опросов экспертов)

\begin{tabular}{|c|c|c|c|}
\hline № варианта & $\begin{array}{c}\text { Прямой экономиче- } \\
\text { ский эффект } E_{\text {dir }}\end{array}$ & $\begin{array}{c}\text { Косвенный } \\
\text { экономический } \\
\text { эффект } E_{\text {indir }}\end{array}$ & Военный эффект $M$ \\
\hline 1 & 1 & 1 & 1 \\
\hline 2 & 1,1 & 1,7 & 1,3 \\
\hline 3 & 1,4 & 0,8 & 0,7 \\
\hline
\end{tabular}

Как показывает табл. 2, с точки зрения прямого экономического эффекта (т. е. экономии, которую получит государство) варианты 2 и 3 оказываются более выгодными, чем базовый. И если большая прямая эффективность варианта 3 имеет под собой очевидную причину (снижение объема инвестиций в развитие импортозамещающих производств благодаря использованию уже существующих поставщиков с отлаженными схемами производства), то более высокая эффективность варианта 2 (предполагающего активное использование частных компаний) по сравнению с вариантов 1 (опирающимся на госкорпорацию) нуждается в специальном обосновании. Эксперты мотивировали более высокую прямую эффективность варианта 2 тем, что она связана с более низкими трансакционными издержками, более высоким качеством управления (которое обеспечивают частные компании) и с возможностью минимизировать коррупционные схемы, которые, к сожалению, характерны для российских структур с государственным участием.

Более высокий косвенный экономический эффект второго варианта по сравнению с первым связан с тем, что в рамках второ- 
го варианта будет выстроена сеть национальных производителей, способных обеспечить российскую промышленность и экономику в целом необходимыми узлами, комплектующими и программными продуктами. Напротив, при реализации первого варианта все участвующие в программе импортозамещения производители будут замкнуты в пределах одной вертикально интегрированной структуры, ориентированной на обслуживание интересов ОПК и слабо связанной с гражданским сектором экономики. Низкая (фактически отрицательная) косвенная эффективность третьего варианта по сравнению с первым объясняется тем, что в третьем варианте развитие национальной промышленности практически не осуществляется.

Интегральный экономический эффект $E_{i n t}$ рассчитывается по формуле:

$$
E_{\text {int }, i}=A E_{d i r, i}+B E_{\text {indir },{ }^{*}}
$$

Beca $A$ и $B$ были установлены экспертно и их значения составляют 0,4 и 0,6. Более высокий вес для косвенного экономического эффекта объясняется тем, что, как было сказано выше, реализация мероприятий по обеспечению технологической независимости отечественного ОПК имеет в качестве стратегической цели развитие полнофункциональной российской промышленности.

Что касается военного эффекта (табл. 2), то он более высок во втором варианте, поскольку при нем выстраивается самодостаточная сеть отечественных производителей, не зависящая от государственной поддержки и государственного заказа. Это обуславливает ее более высокую экономическую стабильность и способность более эффективно обслуживать потребности национальной экономики. Поскольку при третьем варианте зависимость национальной экономики от внешних поставок сохраняется, риски остаются высокими.

В свою очередь, для оценки интегрального военно-экономического эффекта используется формула

$$
M E E_{i}=M_{i} E_{\text {int }, i} .
$$

Итоговые значения интегрального экономического эффекта и военно-экономического эффекта представлены в табл. 3. 
Таблиц̧а 3.

Значения интегрального экономического эффекта и военно-экономического эффекта (составлено Наружным В.Е.)

\begin{tabular}{|c|c|c|}
\hline № варианта & $\begin{array}{c}\text { Интегральный } \\
\text { экономический эффект } E_{\text {int }}\end{array}$ & $\begin{array}{c}\text { Интегральный военно- } \\
\text { экономический эффект } M E E\end{array}$ \\
\hline 1 & 1 & 1 \\
\hline 2 & 1,46 & 1,9 \\
\hline 3 & 1,04 & 0,73 \\
\hline
\end{tabular}

Результаты вычислений показывают, что наиболее предпочтительным вариантом организации собственных станкостроительных производств в нашей стране является второй - формирование государственно-частного партнерства, ориентированного на выпуск станков (значение интегрального экономического $\left(E_{\mathrm{int}}\right)$ и военноэкономического эффектов ( $M E E)$ составляет 1,46 и 1,9, соответственно, при этом значения, большие единицы, имеют также прямой $\left(E_{d i r}\right)$ и косвенный $\left(E_{\text {indir }}\right)$ экономические, а также военный $(M)$ эффект).

Мы можем утверждать следующее:

1. Предложенный нами научно-методический аппарат позволяет принимать решения о выборе оптимальной стратегии в сфере импортозамещения даже при отсутствии точных количественных данных, на основе мнений экспертов;

2. Опрос экспертов показывает, что, несмотря на необходимость обеспечивать прямой экономический эффект, особое внимание все же следует уделять косвенному экономическому эффекту, т. е. фактически выстраиванию самостоятельной промышленности, способной за счет своих ресурсов обеспечивать потребности как ОПК, так и национальной экономики в целом;

3. С организационной точки зрения наиболее предпочтительной формой организации импортозамещающих производств для обеспечения технологической независимости российского ОПК является сетевая кооперации на основе государственно-частного партнерства.

\section{Список литературы}

1. Богатырева С.В., Титов А.Б., Куприянова М.Ю. Экономическая эффективность как основа формирования управленческих решений 
// Экономика и менеджмент систем управления. 2016. Т. 20. № 2.1. C. $116-122$.

2. Бочуров А.А., Курбанов А.Х. Перспективы и проблемы развития отечественного оборонно-промышленного комплекса в современных условиях // Теория и практика сервиса: экономика, социальная сфера, технологии. 2017. № 3. С. 5-9.

3. Вертакова Ю.В., Плотников В.А. Импортозамещение: теоретические основы и перспективы реализации в России // Экономика и управление. 2014. № 11. С. 38-47.

4. Ерасова Е.А., Плотников В.А. Перспективы развития оборонно-промышленного комплекса России в условиях экономических санкций // Экономика и управление. 2015. № 3. С. 22-28.

5. Князьнеделин Р.А. Формирование механизмов управления реализацией государственных заказов на инновационную продукцию как инструмента государственной промышленной политики в обороннопромышленном комплексе // Экономическое возрождение России. 2013. № 1. C. 141-148.

6. Князьнеделин Р.А. Модель экономического обоснования выпуска продукции двойного и гражданского назначения посредством конверсии и диверсификации предприятий оборонно-промышленного комплекса, а также технологического трансфера // Финансовая экономика. 2019. № 1. С. 71-75.

7. Князьнеделин Р.А., Стариков С.В. Реализация стратегии импортозамещения на основе сетевой кооперации // Экономика и предпринимательство. 2015. № 12-4. С. 173-177.

8. Колерова В. Чтобы все завертелось // Эксперт. 2019. № 10. С. 22-25.

9. Стариков С.В. Проблемы использования сетевой кооперации для целей импортозамещения // Многоуровневое общественное воспроизводство: вопросы теории и практики. 2016. № 11. С. 152-158.

10. Стариков С.В. Потенциал применения многоуровневого сетевого партнерства в промышленности как инструмента развития импортозамещающих производств // Управленческое консультирование. 2017. № 8. С. 169-175.

11. Ульянов Н. Взять свое // Эксперт. 2018. № 6. С. 26-31. 


\section{References}

1. Bogatyreva S.V., Titov A.B., Kupriyanova M.Yu. Ekonomicheskaya effektivnost kak osnova formirovaniya upravlencheskikh resheniy [Economic effectiveness as a basis for managerial decisions]. Ekonomika $i$ menedzhment system upravleniya, 2016, V. 20, no 2.1, pp. 116-122.

2. Bochurov A.A., Kurbanov A.Kh. Perspektivy i problemy razvitiya otechestvennogo oboronno-promyshlennogo kompleksa v sovremennykh usloviyakh [Prospects and problems of development of the national defense industrial complex in modern situation]. Teoriya i praktika servisa: ekonomika, sotsial'naya sfera, tekhnologii, 2017, no 3, pp. 5-9.

3. Vertakova Yu.V., Plotnikov V.A. Importozameshchenie: teoreticheskie osnovy i perspektivy realizatsii v Rossii [Substitution of import: theoretical foundations and prospects of implementation in Russia]. Ekonomika i upravlenie, 2014, no 11, pp. 38-47.

4. Erasova E.A., Plotnikov V.A. Perspektivy razvitiya oboronno-promyshlennogo kompleksa Rossii v usloviyakh ekonomicheskikh sanktsiy [Prospects of development of the defense industrial complex of Russia under sanctions]. Ekonomika i upravlenie, 2015, no 3, pp. 22-28.

5. Kniaznedelin R.A. Formirovanie mekhanizmov upravleniya realizatsiey gosudarstvennykh zakazov na innovatsionnuyu produktsiyu kak instruments gosudarstvennoy promyshlennoy politiki v oboronno-promyshlennov komplekse [Formation of mechanisms of management of implementation of state contracts for innovation products as a tool of state industrial policy in the defense industrial complex]. Ekonomicvheskoe vozrozhdenie Rossii, 2013, no 1, pp. 141-148.

6. Kniaznedelin R.A. Model ekonomicheskogo obosnovaniya vypuska produktsii dvoynogo i grazhdanskogo naznacheniya posredstvom konversii i diversifikatsii predpriyatiy oboronno-promyshlennogo kompleksa, a takzhe tekhnologicheskogo transfera [A model of economic substantiation of production of products of double and civil use on the basis of conversion and diversification of companies of defense industrial complex, as well as technological transfer]. Finansovaya ekonomika, 2019, no 1, pp. 71-75.

7. Kniaznedelin R.A., Starikov S.V. Realizatsiya strategii importozameshcheniya na osnove setevoy kooperatsii [Implementation of the strategy of 
import substitution on the basis of networking cooperation]. Ekonomika i predprinimatel'stvo, 2015, no 12-4, pp. 173-177.

8. Kolerova V. Chtoby vse zavertelos [To make everything run]. Ekspert, 2019, no 10, pp. 22-25.

9. Starikov S.V. Problemy ispol'zovaniya setevoy kooperatsii dlya tseley importozameshcheniya [Problems of implementation of networking cooperation for purposes of import substitution]. Mnogourovnevoe obshchestvennoe vosproizvodstvo: voprosy teorii i praktiki, 2016, no 11, pp. 152-158.

10. Starikov S. V. Potentsial primeneniya mnogourovnevogo setevogo partnerstva $\mathrm{v}$ promyshlennosti kak instrumenta razvitiya importozameshchayushchikh proizvodstv [Potential of the use of multi-level networking cooperation in the industry as a tool of development of facilities for substitution of import]. Upravlencheskoe konsul tirovanie, 2017, no 8, pp. 169-175.

11. Ulyanov N. Vziat svoe [To take one's own]. Ekspert, 2018, no 6, pp. 26-31.

\section{ДАННЫЕ ОБ АВТОРАХ}

Бекмурзаев Иса Дуквахович, к.э.н., доцент, и. о. зав. кафедрой «Коммерция и маркетинг»

Чеченский государственный университет

пр. Бульвар Дудаева, 17, г. Грозный, Чеченская Республика, 366007, Российская Федераиия

bekmurzaev71@mail.ru

Курбанов Артур Хусаинович, д.э.н., профессор, профессор кафедры материального обеспечения Военная академия материально-технического обеспечения им. генерала армии А.В. Хрулева наб. Макарова, 8, г. Санкт-Петербург, 199034, Российская Федерация

Наружный Вячеслав Евгеньевич, начальник отдела 249 Военное представительство Министерства обороны Российской Федерации г. Санкт-Петербург 


\section{DATA ABOUT THE AUTHORS}

Bekmurzaev Isa Dukvakhovich, Ph. D., Associate Professor, I.O. Head

Department of Commerce and Marketing

Chechen State University

17, Dudaev Boulevard, Grozny, Chechen Republic, 366007, Russian Federation

bekmurzaev71@mail.ru

Kurbanov Artur Khusainovich, Dr. Sc. (Economics), Professor, Professor of the Chair of Material Supplies

General of the Army A. V. Khrulev Military Academy of Procurement and Logistics

8, Makarova, St. Petersburg, 199034, Russian Federation

Naruzhny Vyacheslav Evgenyevich, head of the department 249

The Military Representation of the Ministry of Defense of Russian Federation

St. Petersburg 